\title{
The long-run effects of monetary policy
}

\author{
Òscar Jordà $^{\dagger} \quad$ Sanjay R. Singh ${ }^{\ddagger} \quad$ Alan M. Taylor ${ }^{\S}$ \\ February 2019
}

\section{Preliminary draft - Not for citation or circulation}

\begin{abstract}
A well-worn tenet holds that monetary policy does not affect the long-run productive capacity of the economy. Merging data from two new international historical databases, we find this not to be quite right. Using the trilemma of international finance, we find that exogenous variation in monetary policy affects capital accumulation, and to a lesser extent, total factor productivity, thereby impacting output for a much longer period of time than is customarily assumed. We build a quantitative mediumscale DSGE model with endogenous TFP growth to understand the mechanisms at work. Following a monetary shock, lower output temporarily slows down TFP growth. Internal propagation of the monetary shock extends the slow down in productivity, and eventually lowers trend output. Yet the model replicates conventional textbook results in other dimensions. Monetary policy can have long-run effects.
\end{abstract}

JEL classification codes: E01, E30, E32, E44, E47, E51, F33, F42, F44

Keywords: monetary policy, interest rates, money neutrality, productivity, hysteresis, trilemma, instrumental variables.

${ }^{\star}$ We are thankful to many, including conference participants who provided very helpful advice on how to improve the paper. Antonin Bergeud graciously shared detailed data from the long-term productivity database created with Gilbert Cette and Rémy Lecat at the Banque de France. We thank RAs for excellent research assistance. All errors are ours. The views expressed in this paper are the sole responsibility of the authors and to not necessarily reflect the views of the Federal Reserve Bank of San Francisco or the Federal Reserve System.

${ }^{\dagger}$ Federal Reserve Bank of San Francisco; and Department of Economics, University of California, Davis (oscar.jorda@sf.frb.org; ojorda@ucdavis.edu).

$\ddagger$ Department of Economics, University of California, Davis (sjrsingh@ucdavis.edu).

$\S$ Graduate School of Business and Department of Economics, University of California, Davis; National Bureau of Economic Research; and Center for Economic Policy Research (amtaylor@ucdavis.edu). 
When coin is in greater plenty, as a greater quantity of if is required to represent the same quantity of goods, it can have no effect either good or bad, taking a nation within itself, any more than it would make an alteration in a merchant's books; if instead of the Arabian method of notation, which requires few characters, he should make use of the Roman, which requires a great many.

- Of Money in Hume (1758)

\section{INTRODUCTION}

Money has long been believed to be neutral in the long-run, as David Hume noted, and as a voluminous literature on monetary economics has argued more formally with rare exceptions. ${ }^{1}$ However, the evidence is less clear cut than the elegant logic of the predominant theories would suggest. Barro (2013) provides evidence that high levels of inflation result in a loss in the rate of economic growth. Work by Caballero, Hoshi, and Kashyap (2008) and Gopinath, Kalemli-Özcan, Karkarabounis, and Villegas-Sánchez (2017) links interest rates to the level of productivity, whereas more recently, Benigno and Fornaro (2018) and Liu, Mian, and Sufi (2018) link low interest rates with the rate of growth of productivity. Our paper follows in this more recent tradition and sets out to investigate the link between monetary policy, the growth rate of productivity, and the growth rate of output in the medium to long term.

In monetary economics, most theories embrace the assumption that an exogenous shock to interest rates has only transitory effects on prices and economic activity (see, e.g., Christiano, Eichenbaum, and Evans, 1999; Ramey, 2016; Coibion, Gorodnichenko, and Ulate, 2017). However, recent research by Jordà, Schularick, and Taylor (2019) suggests that previous measures of monetary shocks might have been endogenous responses to the outlook. They introduce a new instrumental variable based on the trilemma of international finance (see, e.g., Obstfeld, Shambaugh, and Taylor, 2004, 2005; Shambaugh, 2004) to document that monetary shocks have larger and more persistent effects than previously measured, and closer in magnitude to measures obtained with narrative shocks (Romer and Romer, 2004) and market-based, high-frequency identified shocks (Gertler and Karadi, 2015). Moreover, they also document that the effects of monetary policy are state-dependent, extending similar results reported in Tenreyro and Thwaites (2016), Angrist, Jordà, and Kuersteiner (2018), and Barnichon and Matthes (2018).

Using the same instrument as Jordà, Schularick, and Taylor (2019) we show, using historical data since 1870 on 17 advanced economies, that monetary shocks have very long-lasting effects on output and productivity. In particular, we augment the data in Jordà, Schularick, and Taylor (2017) and available at www.macrohistory.net/data, with data on total factor productivity (TFP) and factor

\footnotetext{
${ }^{1}$ See, for example, the discussion of Sidrauski's work by Fischer (1983).
} 
input from Bergeaud, Cette, and Lecat (2016) and available at http://www. longtermproductivity . com. $^{2}$

We investigate this proposition from a variety of angles, by correcting for spillover effects, considering different samples, and examining state dependence as a function of the business cycle, the level of inflation, and importantly, credit. We also examine the soundness of our findings to alternative definitions of monetary shocks based on Romer and Romer (2004) for the postwar United States. The main result is robust to all these modifications. We then look under the hood to examine through what channels is monetary policy is exacting these changes on output growth. We find that the total hours worked response is relatively stable and small. Thus, the main effects on output growth that we uncover appear to come primarily through the responses of real capital accumulation, and to a lesser extent, of utilization adjusted TFP. These results echo the important early findings by Evans (1992) who cast doubt on the exogeneity of TFP shocks, a key tenet of mainstream DSGE models, finding that money, interest rates, and government spending Granger-caused these impulses.

Motivated by these findings, we build a quantitative medium-scale DSGE model with endogenous TFP growth to understand the mechanisms at work. TFP growth deviates from the exogenous trend whenever output is different from potential output. A contractionary monetary policy shock lowers output temporarily producing a slowdown in TFP growth. Under a standard Taylor rule, the temporary slowdown in TFP growth accumulates to yield permanently lower trend levels of output and capital. The model can generate this medium run effect on GDP while replicating the conventional textbook results, namely the utilization rates of labor and capital fall temporarily, and capital to TFP ratio exhibits a hump-shaped response. In our empirical analysis, we corroborate these conventional results (Christiano, Eichenbaum, and Evans, 2005) for the historical sample.

Our paper is also related to the recent literature that emphasizes slow recovery following the Great Recession due to endogenous productivity growth (Anzoategui, Comin, Gertler, and Martinez, 2018; Bianchi, Kung, and Morales, 2019), labor force participation (Erceg and Levin, 2014; Galí, 2016), or skill depletion (Kiyotaki and Zhang, 2017). Of these, Moran and Queraltó (2018) uses three equation VAR models to emphasize an empirical link between TFP growth and monetary policy shocks. We differ in two important ways. One, we investigate and establish that monetary policy shocks can affect level of GDP, capital stock as well as TFP in a panel of 17 countries spanning hundred years. Two, we use externally identified shocks instead of a ordering restrictions to identify monetary policy shocks. Our analysis further provides answer to questions raised by policymakers including Chair Yellen (2016) recently. ${ }^{3}$ Aggregate demand shocks, particulary monetary policy shocks, do indeed have long-lasting effects on the level of output, capital stock and TFP in the

\footnotetext{
${ }^{2}$ We are particularly thankful to Antonin Bergeaud for sharing some of the disaggregated series from their database that we used to construct our own series of adjusted TFP.

3"The first question I would like to pose concerns the distinction between aggregate supply and aggregate demand: Are there circumstances in which changes in aggregate demand can have an appreciable, persistent effect on aggregate supply? ... More research is needed, however, to better understand the influence of movements in aggregate demand on aggregate supply."
} 
economy.

As Lucas (1996) confessed in his Nobel lecture, in seeking to understand how changes in the conduct of monetary policy can influence inflation, employment, and production: "So much thought has been devoted to this question and so much evidence is available that one might reasonably assume that it had been solved long ago. But this is not the case..." This paper has not only important implications for the conduct of monetary policy, it also makes a contribution in furthering our understanding of how monetary economies work.

\section{DATA AND SERIES CONSTRUCTION}

The empirical features motivating our analysis rest on two major international and historical databases. Data on macro aggregates and financial variables, including assumptions on exchange rate regimes and capital controls can be found in www.macrohistory.net/data. This database covers 17 advanced economies reaching back to 1870 at annual frequency. Detailed descriptions of the sources of the variables contained therein, their properties, and other ancillary information are discussed in Jordà, Schularick, and Taylor (2017) and Jordà, Schularick, and Taylor (2019), as well as references therein. Importantly, we will rely on the trilemma instrument discussed in Jordà, Schularick, and Taylor (2016), and more recently, Jordà, Schularick, and Taylor (2019) as the source of exogenous variation in interest rates. We refer the reader to the last reference for a detailed analysis and proceed from hereon without further discussion on the instrument construction.

The second important source of data relies on the work by Bergeaud, Cette, and Lecat (2016) and available at http://www. longtermproductivity.com. This historical database adds to our main database observations on total factor productivity per hour worked, labor productivity per hour worked, and capital intensity. In addition, we construct time-varying capital and labor utilization corrected series using the procedure discussed in Imbs (1999) with the raw data from Bergeaud, Cette, and Lecat (2016) to construct our own series. We went back to the original sources so as to more carefully filter out cyclical variation in input utilization rates in the context of a richer production function that allows for factor hoarding. We will explain the details of this correction below.

\section{Monetary Shocks have long lasting EFFECTS}

\subsection{Empirical approach}

The basic empirical approach relies on local projections (Jordà, 2005) estimated with instrumental variables (LPIV). Several applications of these methods are available in the literature, though a more general discussion of the method can be in Ramey (2016) and Stock and Watson (2018). Based on 
Jordà, Schularick, and Taylor (2019), we estimate in particular:

$$
y_{i, t+h}=\alpha_{i}+\Delta r_{i, t} \beta_{h}+x_{i, t} \gamma_{h}+v_{i, t+h} ; \quad h=0,1, \ldots, H ; i=1, \ldots, N ; t=t_{0}, \ldots, T
$$

where $y_{i, t+h}$ is the outcome variable for country $i$ observed $h$ periods from today; $\alpha_{i}$ are country fixed effects, $\Delta r_{i, t}$ refers to the change in the short-term government bond (3-months in duration), our stand-in for the policy rate which we will instrument with $z_{i, t}$, the trilemma instrument borrowed from Jordà, Schularick, and Taylor (2019) as discussed earlier; and $\boldsymbol{x}_{i, t}$ collects all additional controls

including lags of the outcome and interest rates, as well as lagged values of other macro aggregates. Moreover, we control for global business cycle effects through a global GDP control variable to parsimoniously soak up time effects. We estimate Equation 1 with instrumental variable methods and report cluster robust standard errors.

\subsection{Main results}

The main story in the paper can be illustrated with the response of GDP per capita to a shock to domestic interest rates using the trilemma instrument. Before we show the main results, we highlight the value of our instrumental variable by providing a comparison of the response of GDP per capita to a shock in the short-term domestic interest rate calculated using selection-onobservables identification versus identification with the trilemma instrument. This is shown in Table 1 . The table reports the coefficient estimates of the impulse response calculated with each identification approach for the full and post-WW2 samples. Note that the label LP-OLS refers to identification via selection, $L P-I V$ to the trilemma instrument identification. The samples are restricted to pegging economies to match the samples in both cases.

Table 1 is organized as follows. We provide the coefficient estimates by row and provide a test of the null hypothesis that LP-OLS and LP-IV estimates are equivalent for the two samples considered: full and post-WW2. The differences between identification schemes could not be starker. Both are economically and statistically, but the $L P-I V$ response is considerably larger at all horizons (except $h=0$ for the post-WW2 sample). We display these results graphically in Figure 1.

Regardless of the sample used, a 1 percentage point increase in domestic short-term interest rates have sizable and long-lasting effects on per capita GDP. In the full sample, GDP per capita declines by over 6 percent relative to period 0 over 12 years. The effect, while still large, is considerably more muted in the post-WW2 sample. The drop 12 years after impact is about half, at 3 percent. This is a far cry from traditional notions of long-run neutrality found in the literature.

What is the source of this persistent decline? We decompose the decline in GDP into its components, namely, total hours worked (that is, employees times number of hours per employee); capital stock per capita (the sum of capital measured in machines and buildings per capita); and utilization adjusted total factor productivity (TFP). Using the Imbs (1999) correction, we decompose the Solow residual (raw TFP from a Cobb-Douglas production function $Y=A K^{\alpha} L^{1-\alpha}$ ) into factor- 
Table 1: LP-OLS vs. LP-IV. Attenuation bias of real GDP per capita responses to interest rates. Trilemma instrument. Matched samples

Responses of real GDP per capita at years 0 to $10(100 \times \log$ change from year 0 baseline $)$.

\begin{tabular}{|c|c|c|c|c|c|c|}
\hline \multirow[b]{2}{*}{ Year } & \multicolumn{2}{|c|}{ (a) Full Sample } & \multirow{2}{*}{$\begin{array}{c}\text { OLS-IV } \\
p \text {-value } \\
\text { (3) }\end{array}$} & \multicolumn{2}{|c|}{ (b) Post-WW2 } & \multirow{2}{*}{$\begin{array}{c}\text { OLS-IV } \\
p \text {-value } \\
\text { (6) }\end{array}$} \\
\hline & $\begin{array}{c}\text { LP-OLS } \\
\text { (1) }\end{array}$ & $\begin{array}{l}\text { LP-IV } \\
(2)\end{array}$ & & $\begin{array}{c}\text { LP-OLS } \\
(4)\end{array}$ & $\begin{array}{l}\text { LP-IV } \\
(5)\end{array}$ & \\
\hline$h=0$ & $\begin{array}{c}0.07^{* * *} \\
(0.03)\end{array}$ & $\begin{array}{l}-0.07 \\
(0.09)\end{array}$ & 0.09 & $\begin{array}{l}0.04^{* *} \\
(0.02)\end{array}$ & $\begin{array}{c}0.09 \\
(0.06)\end{array}$ & 0.47 \\
\hline$h=2$ & $\begin{array}{l}-0.28^{*} \\
(0.16)\end{array}$ & $\begin{array}{c}-1.72^{* * *} \\
(0.34)\end{array}$ & 0.00 & $\begin{array}{l}-0.25^{*} \\
(0.13)\end{array}$ & $\begin{array}{c}-1.47^{* * *} \\
(0.38)\end{array}$ & 0.00 \\
\hline$h=4$ & $\begin{array}{l}-0.16 \\
(0.26)\end{array}$ & $\begin{array}{c}-2.53^{* * *} \\
(0.50)\end{array}$ & 0.00 & $\begin{array}{l}-0.08 \\
(0.21)\end{array}$ & $\begin{array}{c}-1.83^{* * *} \\
(0.57)\end{array}$ & 0.00 \\
\hline$h=6$ & $\begin{array}{l}-0.06 \\
(0.29)\end{array}$ & $\begin{array}{c}-2.87^{* * *} \\
(0.66)\end{array}$ & 0.00 & $\begin{array}{c}0.02 \\
(0.23)\end{array}$ & $\begin{array}{c}-2.37^{* * *} \\
(0.55)\end{array}$ & 0.00 \\
\hline$h=8$ & $\begin{array}{l}-0.36 \\
(0.29)\end{array}$ & $\begin{array}{c}-3.55^{* * *} \\
(0.84)\end{array}$ & 0.00 & $\begin{array}{c}0.10 \\
(0.22)\end{array}$ & $\begin{array}{c}-2.04^{* * *} \\
(0.55)\end{array}$ & 0.00 \\
\hline$h=10$ & $\begin{array}{l}-0.40 \\
(0.35)\end{array}$ & $\begin{array}{c}-4.05^{* * *} \\
(1.08)\end{array}$ & 0.00 & $\begin{array}{c}0.26 \\
(0.24)\end{array}$ & $\begin{array}{c}-1.63^{* * *} \\
(0.62)\end{array}$ & 0.00 \\
\hline KP weak IV & & 79.66 & & & 84.86 & \\
\hline$H_{-} 0: L A T E=0$ & 0.00 & 0.00 & & 0.00 & 0.00 & \\
\hline Observations & 607 & 607 & & 482 & 482 & \\
\hline
\end{tabular}

Notes: ${ }^{* * *} p<0.01,{ }^{* *} p<0.05,{ }^{*} p<0.1$. Cluster robust standard errors in parentheses.Full sample: $1890-2015$ excluding WW1: 1914 - 1919 and WW2: 1939 - 1947. Post WW2 sample: 1948 - 2015. Matched sample indicates LP-OLS sample matches the sample used to obtain LP-IV estimates. KP weak IV refers to the Kleibergen-Paap test for weak instruments. $H_{0}$ $:$ subATE $=0$ refers to the $p$-value of the test of the null hypothesis that the coefficients for $h=0, \ldots, 10$ are jointly zero for a given subpopulation. $O L S=I V$ shows the $p$-value for the Hausmann test of the null that OLS estimates equal IV estimates. See text. 
Figure 1: Baseline response to 10o bps trilemma shock: Real GDP per capita

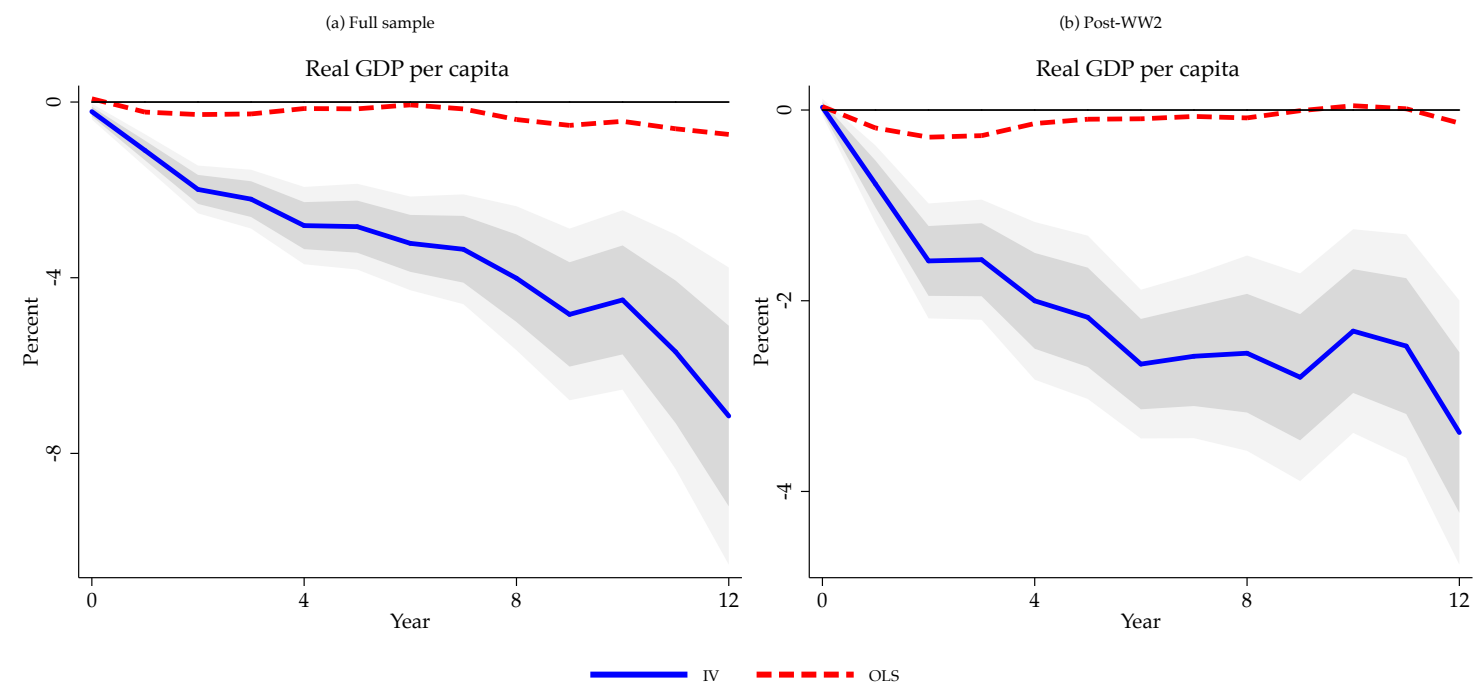

Notes: Response to a 100 bps shock in domestic interest rate instrumented with the trilemma. Responses for pegging economies. Full sample: 1890-2015 (World Wars excluded). Post-WW2 sample: 1948-2015. See text.

utilization (capital and labor) and the subsequent residual is labeled as the utilization adjusted TFP.

Figure 2 displays the responses of each of these components to the same shock to the domestic short-term interest rate instrumented with the trilemma, both for the full and the post-WW2 samples. The figure displays the responses of total hours worked, capital and TFP adjusted without error bands to provide a clearer sense of the dynamic paths. A more detailed figure is provided in the Appendix, which includes the error bands.

Several features deserve mention. Figure 2 shows that there are similar declines in capital and utilization adjusted TFP whereas total hours worked exhibits a much flatter pattern. Because capital enters the production function with a smaller weight, it should be clear from the figure that most of the decline in per capita GDP is explained by utilization adjusted TFP, and then capital, with total hours worked mostly flat. To be sure, the response of hours worked conforms well with the textbook response to a monetary shock. Total hours fall in the short-run, but then recover quickly and remain mostly flat.

Capital accumulation also follows textbook dynamics in the short-run. The response is initially muted but builds up over time. But unlike the textbook model, capital does not appear to recover even 12 years after the shock. Similarly, utilization adjusted TFP appears to follow textbook dynamics: it falls gradually rather than suddenly. Over time, the decline in utilization adjusted TFP accelerates, ending at a level 3 (1) percent lower in full (post WW2) sample by year 12 relative to year 0 . Figure 3 presents the evolution of capital to utilization adjusted TFP ratio in response to the trilemma shock. The hump-shaped response replicates the conventional justification for including 
Figure 2: Baseline response to 1oo bps trilemma shock: Real GDP per capita and components

(a) Full sample

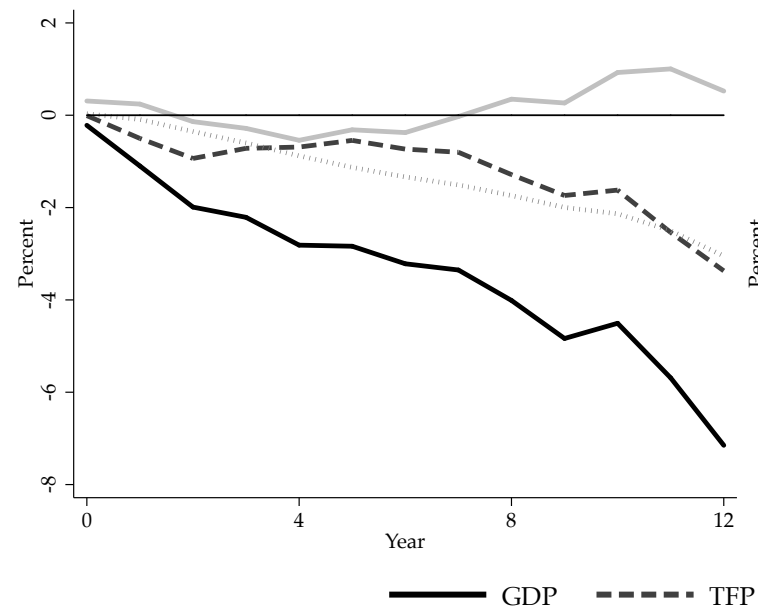

(b) Post-WW2

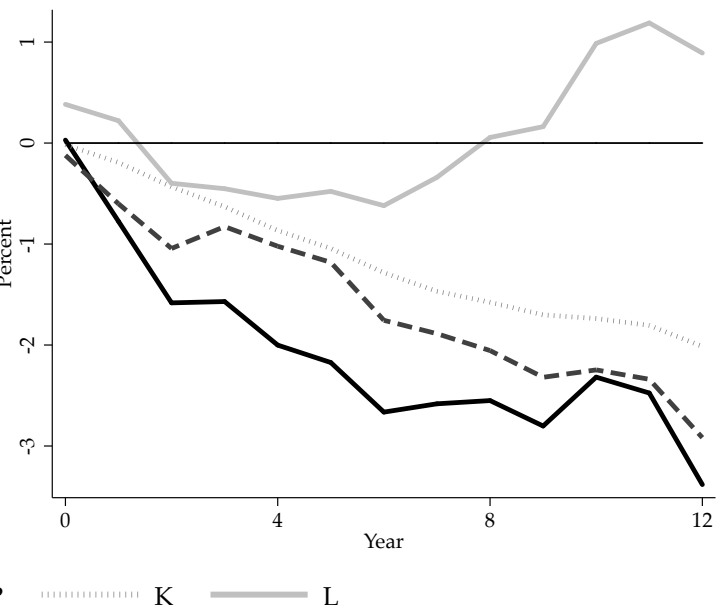

Notes: Response to a 100 bps shock in domestic interest rate instrumented with the trilemma. Responses for pegging economies. Full sample: 1890-2015 (World Wars excluded). Post-WW2 sample: 1948-2015. See text.

investment adjustment costs in typical DSGE models (Christiano, Eichenbaum, and Evans, 2005).

We present the responses of the various components of the Solow residual in Figure 4 for both the full and post-WW2 samples. Utilization rates of labor and capital exhibit cyclical dynamics: falling in the short-run and then recovering back to zero. In a sense, this pattern is mechanical. It reflects the restriction imposed on the calculation that utilization rates must return to zero eventually (Imbs, 1999). We later show the robustness of using a more commonly used utilization adjusted TFP series constructed by Fernald (2014) for the post-WW2 US, which requires more detailed data than is available for the historical panel of 17 countries. Reassuringly, the results for utilization adjusted TFP using the two methods are qualitatively similar.

One explanation for the long-lasting effects of the monetary shock could be that domestic interest rates remain elevated for a long period of time as well. In other words, persistence is generated by a delayed response in interest rates. A simple check of this proposition can be done in two steps. Figure 5 shows that the short-term real interest rate does indeed take approximately 8 years to return to zero, while the nominal interest rate returns to zero after 4 years. The response of nominal interest rate is typical of what has been reported often in the literature (see, e.g., Christiano et al., 1999; Ramey, 2016). Secondly, we can calculate the responses of the main variables normalized by the response of interest rates over time to sterilize the dynamics of interest rates themselves. This is no different than calculating a multiplier (see, e.g., Ramey, 2016; Ramey and Zubairy, 2018).

Thus, in Figure 6 we show the ratio of the cumulative change in GDP to the area under the real interest rate path in Figure 5 In a given period, the difference in the level of real interest rate relative to the counterfactual path measures the tightness of monetary policy. We consider these cumulative 
Figure 3: Baseline response to 10o bps trilemma shock: Capital to utilization adjusted TFP

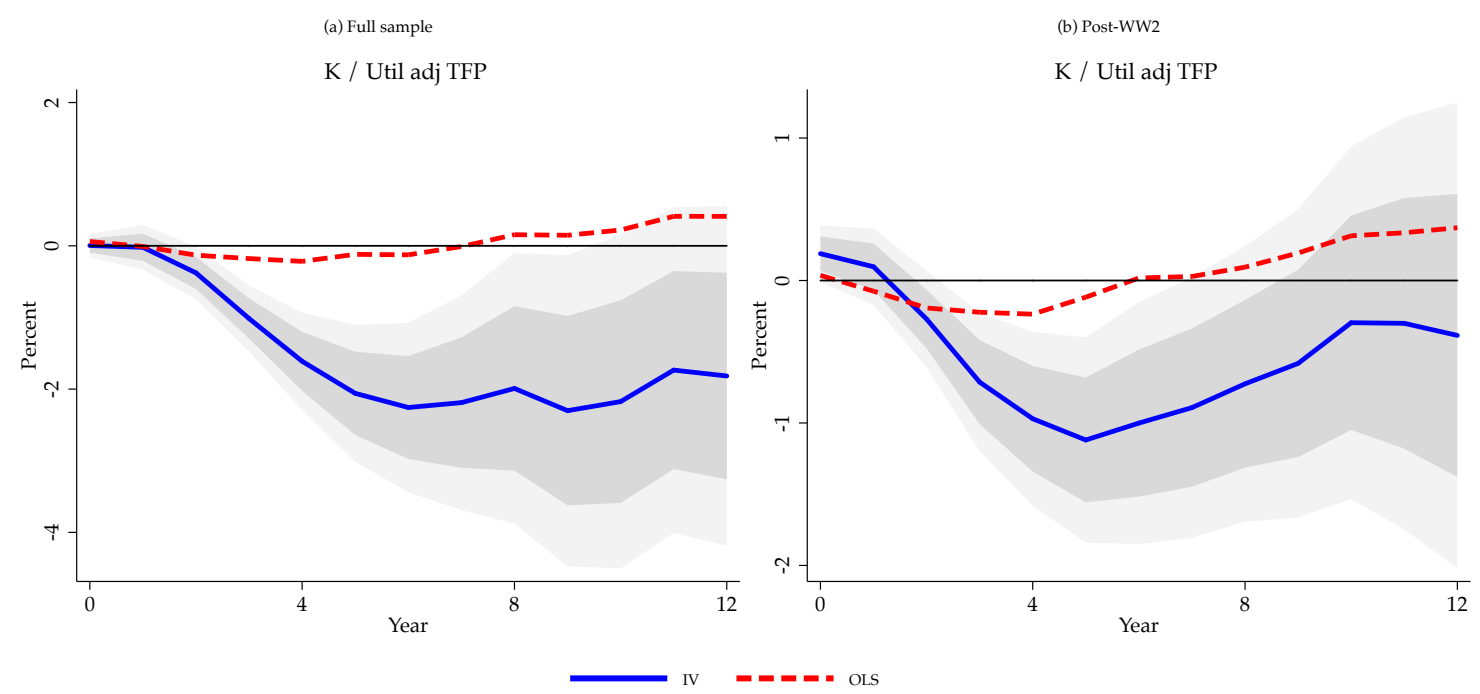

Notes: Response to a 100 bps shock in domestic interest rate instrumented with the trilemma. Responses for pegging economies. Full sample: 1890-2015 (World Wars excluded). Post-WW2 sample: 1948-2015. See text.

Figure 4: Baseline response to 10o bps trilemma shock: TFP and utilization

(a) Full sample

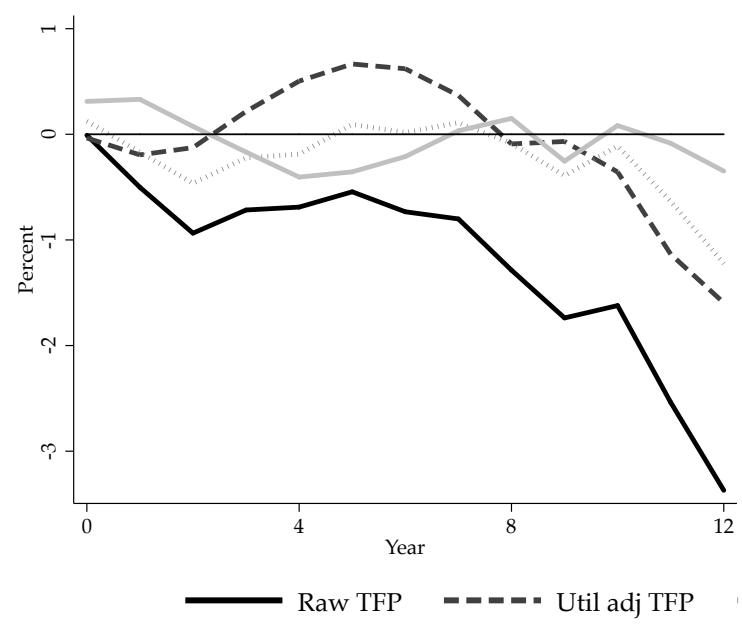

(b) Post-WW2

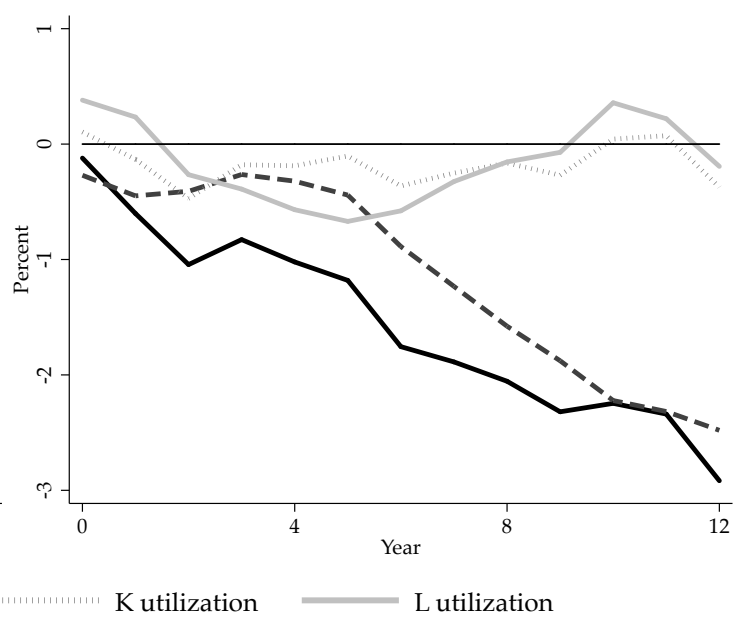

Notes: Response to a 100 bps shock in domestic interest rate instrumented with the trilemma. Responses for pegging economies. Full sample: 1890-2015 (World Wars excluded). Post-WW2 sample: 1948-2015. See text. 
gaps as a measure of overall monetary policy tightness (the area under the solid line in Figure 5). By year 12 , the multiplier is -1.3 in the full sample and -1.4 in the post-WW2 sample, virtually identical and sizable.

\subsection{Is the US different?}

The US for most of our historical sample is not a pegging economy (with the exception of the Gold standard years before WWI). It is the quintessential base country for many economies in our sample. For this reason, the trilemma instrument mechanically sets aside any information coming from the US economy during estimation. It is natural to wonder the extent to which US data conforms with the patterns presented so far.

In this section, we examine US data post-WW2. This allows us to incorporate three useful modifications. First, we use higher frequency quarterly data. Second, we use the alternative utilization adjusted series for TFP constructed by Fernald (2014). Third, in order to achieve identification we rely on the instrumental variable constructed by Romer and Romer (2004) based on the Federal Reserve staff's implied forecast errors for the policy rate, and extended to recent years by Wieland and Yang (2016). It turns out that results based on U.S. data largely confirm the results we reported in the previous section for non-U.S. pegging economies.

Figure 7 plots the the path of real GDP along with its three components: total hours worked, capital, and utilization adjusted TFP. The responses are qualitatively similar to those in the long-run panel, although the amplitudes are more muted. Quarterly data is naturally noisier than yearly data, but smoothing over a temporary recovery in GDP 4 to 5 years after the shock, real GDP ends nearly one percent lower 8 years after impact. Utilization adjusted TFP and hours exhibit a similar u-shaped pattern, with TFP nearly back to zero by year 8 . Strikingly, capital accumulation exhibits a protracted decline over the entire period, ending about 1.25 percent lower after eight years.

\section{A MODEL OF HYSTERESIS}

Impulse responses calculated with standard methods that internally favor reversion to the mean will tend to underestimate the value of the response at longer horizons. By relying on local projections, we allow the data to more directly speak as to its long-run properties. The evidence presented in the previous sections strongly indicate that these long-run effects are important and require further investigation. In order to think through a possible mechanism that explains our empirical findings, we augment a textbook New Keynesian model with endogenous growth in a stylized manner. We present the different components of the model in the next few sections, starting with the production side of the economy. 
Figure 5: Baseline response to 10o bps trilemma shock: Short term real interest rate
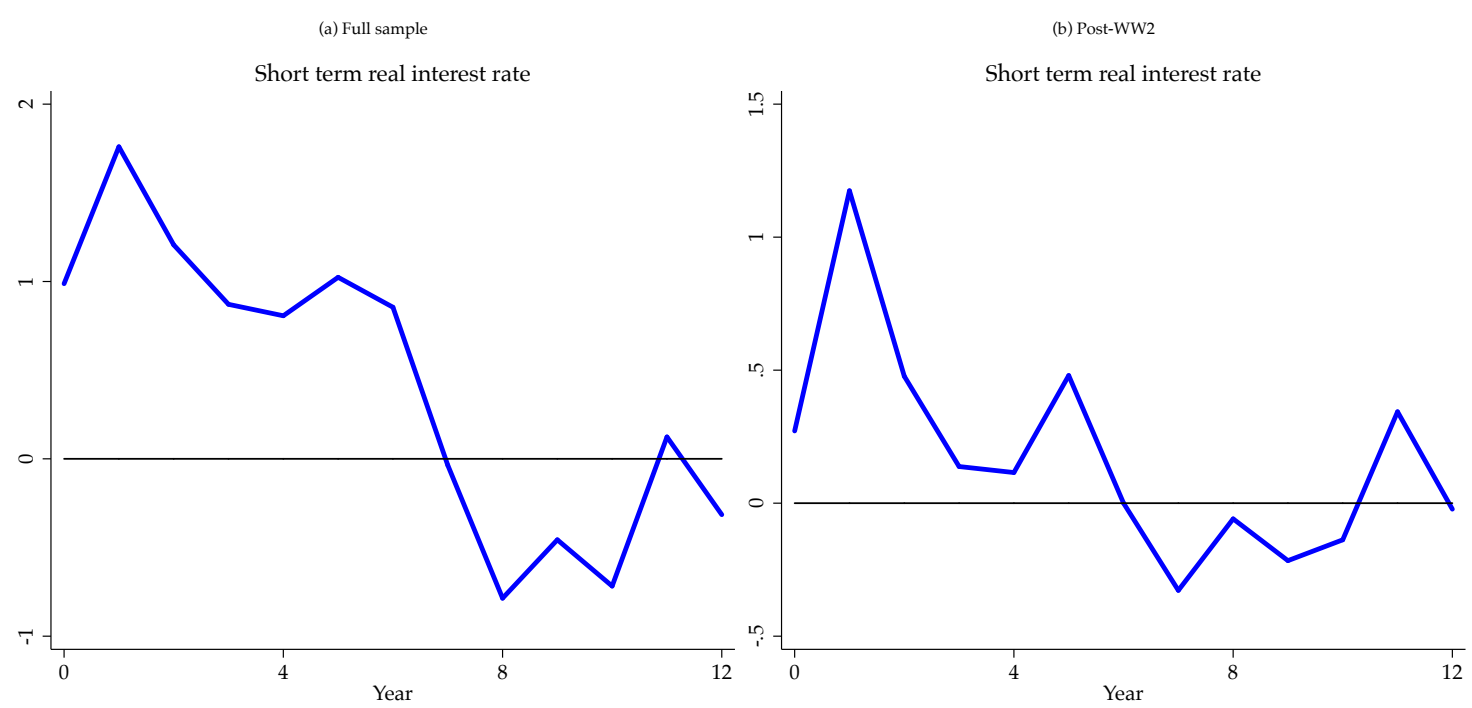

Notes: Response to a 100 bps shock in domestic interest rate instrumented with the trilemma. Responses of short term real interest rate for pegging economies. Inflation expectations constructed from the impulse response of consumer price level index to the same trilemma shock. Full sample: 1890-2015 (World Wars excluded). Post-WW2 sample: 1948-2015. See text.

Figure 6: Cumulative change in real GDP per capita / Cumulative short term expected real interest rate gap

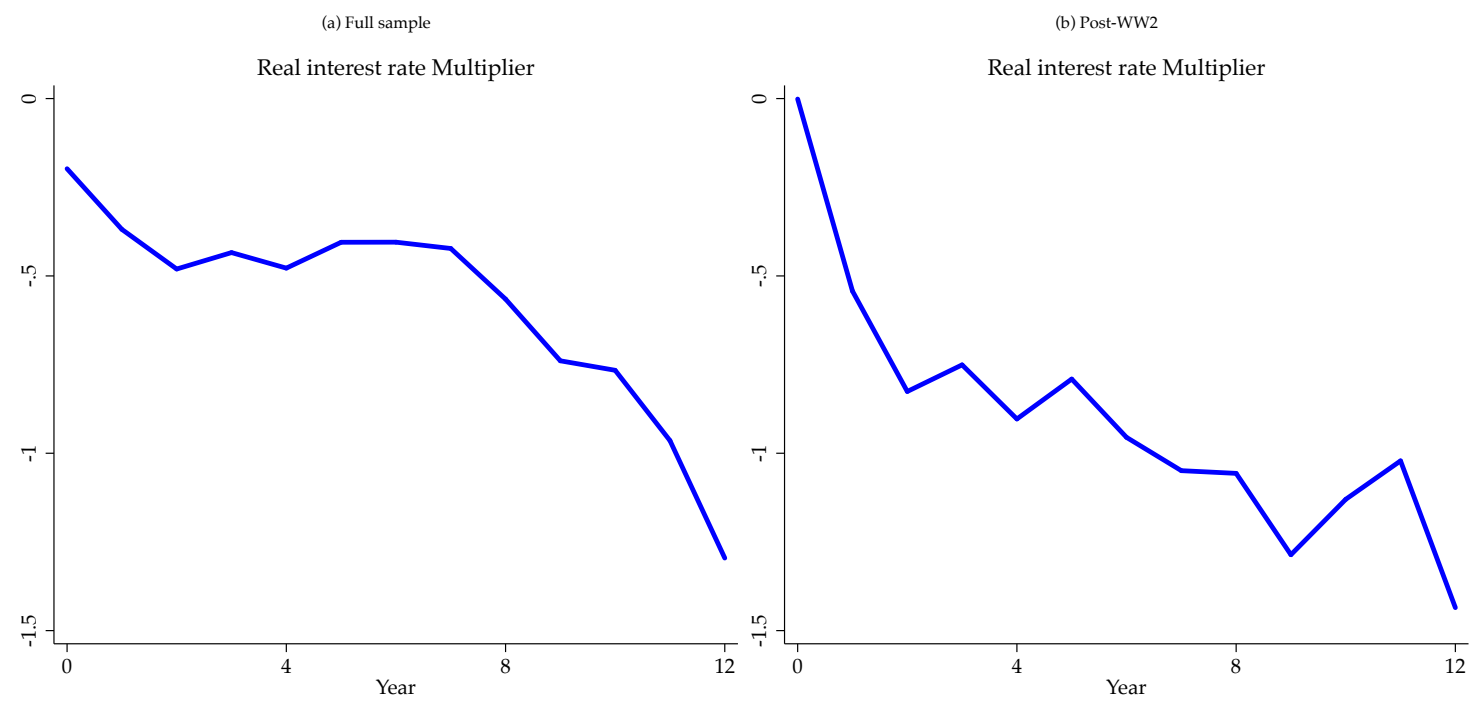

Notes: Response to a 100 bps shock in domestic interest rate instrumented with the trilemma. Plots path of cumulative change in real GDP per capita divided by cumulative change in short term nominal interest rate for pegging economies. Full sample: 1890-2015 (World Wars excluded). Post-WW2 sample: 1948-2015. See text. 
Figure 7: Baseline response to 10o bps Romer and Romer (2004) shock: US postwar data

Instrument: Romer \& Romer (2004) residuals

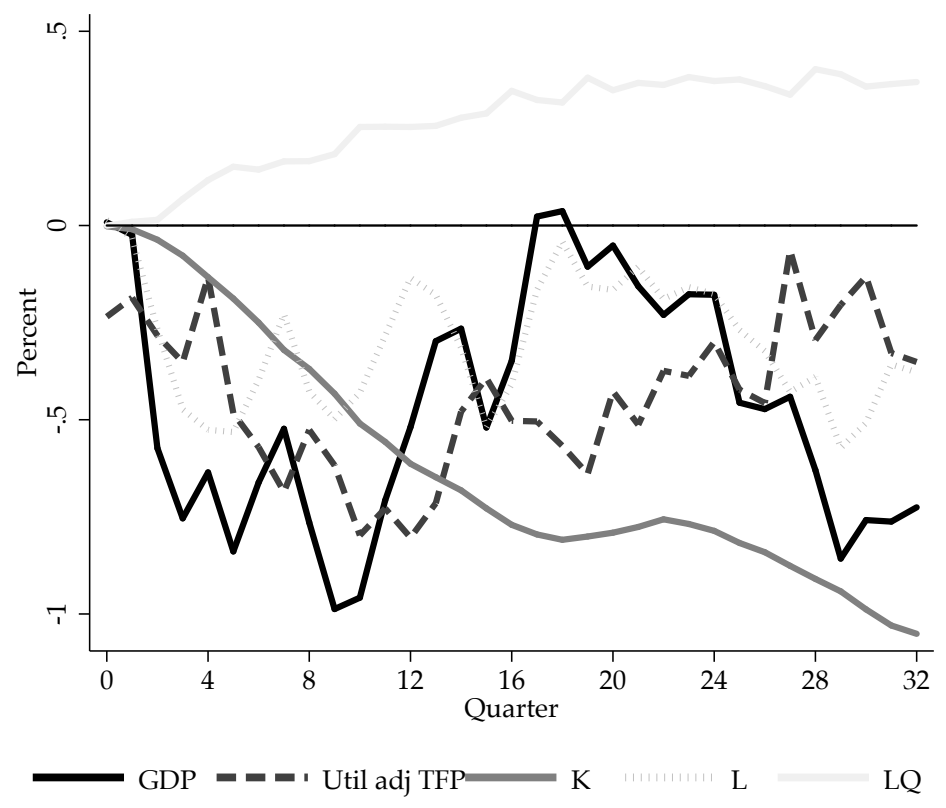

Notes: Response to a 100 bps shock in overnight federal funds rate rate instrumented with policy forecast residuals (Romer and Romer, 2004; Wieland and Yang, 2016). Responses of real GDP, capital stock, total hours worked, labor composition/quality, and raw TFP for US. Quarterly sample: 1969-Q1: 2007-Q4. Quarterly data series are taken from Fernald (2014). See text.

\subsection{Monopolistically Competitive Producers}

Assume there is a continuum of differentiated intermediated good producers that sell the intermediate good $Y_{k t}$. These goods can be aggregated into a Dixit-Stiglitz final composite good $Y_{t}$ as follows:

$$
Y_{t}=\left[\int_{0}^{1} Y_{k t}^{\frac{1}{1+\lambda p}} d k\right]^{1+\lambda_{p}}
$$

where $\lambda_{p}>0$ is the price markup. The iso-elastic demand for intermediate good $k$ is given by:

$$
Y_{k t}=\left(\frac{P_{k t}}{P_{t}}\right)^{-\frac{1+\lambda_{p}}{\lambda_{p}}} Y_{t}
$$

The zero profit condition for competitive final good producers implies that the aggregate price index is

$$
P_{t}=\left[\int_{0}^{1} P_{k t}^{-\frac{1}{\lambda_{p}}} d k\right]^{-\lambda_{p}}
$$


Each intermediate good $k$ is produced by a price-setting monopolist using labor $L_{k t}$ and physical capital $K_{k t}{ }^{4}$ :

$$
Y_{k t}=\left(Z_{t} L_{k t}\right)^{1-\alpha} K_{k t}^{\alpha}
$$

where $Z_{t}$ is the aggregate TFP. The variable $Z_{t}$ denotes a non-stationary TFP series that we describe in the next subsection. ${ }^{5}$ Firms may not be able to adjust their price in a given period, but they will always choose inputs to minimize total cost each period. The cost minimization yields the input demand functions.

$$
\begin{gathered}
W_{t}=(1-\alpha) m c_{k t} F_{t}^{1-\alpha}\left(\frac{K_{k t}}{L_{k t}}\right)^{\alpha} \\
R_{t}^{k}=\alpha m c_{k t} F_{t}^{1-\alpha}\left(\frac{K_{k t}}{L_{k t}}\right)^{\alpha-1}
\end{gathered}
$$

The first order condition implies that the capital labor ratio at the firm level is independent on firm-specific variables:

$$
\frac{K_{k t}}{L_{k t}}=\frac{K_{t}}{L_{t}}=\frac{\alpha}{1-\alpha} \frac{W_{t}}{R_{t}^{k}}
$$

Thus, (nominal) marginal cost is independent of firm specific variables:

$$
P_{t} m c_{k t}=P_{t} m c_{t}=\frac{1}{F_{t}^{1-\alpha}}\left(\frac{R_{t}^{k}}{\alpha}\right)^{\alpha}\left(\frac{W_{t}}{1-\alpha}\right)^{1-\alpha}
$$

Each firm $k$ is assumed to set prices on a staggered basis following Calvo (1983). With probability $\left(1-\theta_{p}\right)$, a firm adjusts its price independent of previous history. A resetting firm chooses $\tilde{P}_{k t}$ to maximize:

$$
\mathbb{E}_{t} \sum_{s=t}^{\infty} \theta_{p}^{s-t} Q_{t, s}\left[\frac{\tilde{P}_{k t}}{P_{s}}-m c_{s}\right] Y_{s}(k)
$$

subject to demand for its product

$$
Y_{k t}=\left(\frac{P_{k t}}{P_{t}}\right)^{-\frac{1+\lambda_{p}}{\lambda p}} Y_{t}
$$

where the stochastic discount factor in period $s$ relative to period $t$ is given by:

$$
Q_{t, s}=\beta^{s-t} \frac{\Lambda_{s}}{\Lambda_{t}} \frac{P_{t}}{P_{s}}
$$

\footnotetext{
${ }^{4}$ We can append fixed cost in the production function to eliminate steady state profits. This is usually done to justify no entry and exit in the steady state in a DSGE model (Christiano et al. 2005, Justiniano, Primiceri, and Tambalotti 2013, Smets and Wouters 2007). In a micro-founded model of growth, positive rents are needed to incentivize investment in growth (Romer, 1990).

${ }^{5}$ Relative to the conventional literature, we will allow for an endogenous relationship between TFP growth and output gap.
} 
and $\Lambda_{t}$ is the marginal utility of consumption defined later. The first order condition is :

$$
\mathbb{E}_{t} \sum_{s=t}^{\infty} \theta_{p}^{s-t} Q_{t, s}\left[\frac{\tilde{P}_{t}}{\Pi_{t, s}}-\left(1+\lambda_{p}\right) m c_{s}\right]\left(\frac{\tilde{P}_{t}}{\Pi_{t, s}}\right)^{-\frac{1+\lambda_{p}}{\lambda_{p}}} Y_{s}=0
$$

By the law of large numbers, the law of motion of the aggregate price index $P_{t}$ is given by:

$$
P_{t}^{\frac{1}{\lambda_{p}}}=\left(1-\theta_{p}\right)\left(\tilde{P}_{t}\right)^{\frac{1}{\lambda_{p}}}+\theta_{p} P_{t-1}^{\frac{1}{\lambda_{p}}}
$$

\subsection{Hysteresis effects}

In order to be able to capture the empirical features describe in the previous sections, we examine a richer specification of the low of motion for total factor productivity than is conventional. In particular, we assume that the law of motion for $Z_{t}$ is:

$$
\log Z_{t}=\log Z_{t-1}+\mu_{t}+\eta \log \left(Y_{t-1} / Y_{t-1}^{f, t-1}\right)
$$

where $\mu_{t}$ is the exogenous component of the TFP growth rate, that may be subject to trend shocks. $Y_{t-1}^{f, t-1}$ is the flexible price level of output in period $t-1$ conditional on $Z_{t-1}$, and will be referred to as the potential output at time $t-1$. The second component denotes the endogenous component of TFP growth, where $\eta$ is the elasticity of TFP growth rate with respect to fluctuations in output due to nominal rigidities. We refer to this as the hysteresis elasticity (to be consistent with DeLong and Summers 2012).

The above law of motion allows business cycles to affect TFP growth rate only in the presence of nominal rigidities or inadequate stabilization. For clarity, we employed this reduced form equation. A micro-founded model of innovation and productivity growth that yields this exact representation under monetary policy shocks can be found in the recent literature embedding endogenous growth into DSGE models (Bianchi et al., 2019; Garga and Singh, 2016). The effects of business cycles on TFP growth rate that are unrelated to nominal rigidities can be denoted by time varying values of $\mu_{t}$, which may depend on other shocks (markup shocks, stationary TFP shocks, discount factor shocks, capital quality shocks etc.). For ease of exposition, we only focus on the hysteresis effects induced by the presence of nominal rigidities and treat $\mu_{t}$ to be an exogenous series. Movements in this series can be used to induce state-dependent hysteresis effects of monetary policy shocks.

This functional dependence creates a role for hysteresis stabilization by central banks in a reduced form manner (Yellen, 2016). Furthermore, our empirical analysis provides a measure of $\eta{ }^{6}$ Long-run effects of monetary policy shocks depend on the value of $\eta$.

\footnotetext{
${ }^{6}$ Theoretically, there is no apriori reason to expect $\eta$ to be positive. While a 'cleansing' effect of recessions may induce counter-cyclicality, recessions may reduce funding access to firms to conduct R\&D, skill development, and learning-by-doing. The sign on the cyclicality of TFP misallocation is also ambiguous and depends on the assumptions in a model.
} 


\subsection{Households}

Rest of the model components are standard. We briefly summarize them here and leave the detailed derivations to the appendix.

\subsubsection{Households}

Each household supplies differentiated labor indexed by $j$. Household $j$ chooses consumption $C_{t}$, risk-free nominal bonds $B_{t}$, investment $I_{t}$ and capital utilization $u_{t}$ to maximize the utility function, with external habits over consumption:

$$
\mathbb{E}_{t} \Sigma_{s=t}^{\infty} \beta^{s-t}\left[\log \left(C_{j, s}-h C_{j, s-1}\right)-\frac{\omega}{1+v} L_{j, s}^{1+v}\right]
$$

where $h$ is the degree of habit formation, $v>0$ is the inverse Frisch elasticity of labor supply, $\omega>0$ is a parameter that pins down the steady-state level of hours, and the discount factor $\beta$ satisfies $0<\beta<1$. We assume perfect consumption risk sharing across the households. As a result, household's budget constraint in period $t$ is given by

$$
P_{t} C_{t}+P_{t} I_{t}+B_{t+1}=B_{t}\left(1+i_{t}\right)+B_{j, t}^{S}+\left(1+\tau^{w}\right) W_{t} L_{j, t}+\Gamma_{t}+T_{t}+R_{t}^{K} u_{t} K_{t}^{u}-P_{t} a\left(u_{t}\right) K_{t}^{u}
$$

where $I_{t}$ is investment, $B_{j, t}^{S}$ is the net cash-flow from household $j$ 's portfolio of state-contingent securities. Labor income $W_{t} L_{j, t}$ is subsidized at a fixed rate $\tau_{w}$. Households own an equal share of all firms, and thus receive $\Gamma_{t}$ dividends from profits. Finally, each household receives a lump-sum government transfer $T_{t}$. Since households own the capital and choose the utilization rate, the amount of effective capital that the households rent to the firms at nominal rate $R_{t}^{K}$ is :

$$
K_{t}=u_{t} K_{t}^{u}
$$

The (nominal) cost of capital utilization is $P_{t} a\left(u_{t}\right)$ per unit of physical capital. As in the literature (Smets and Wouters 2007) we assume $a(1)=0$ in the steady state and $a^{\prime \prime}>0$. Following Christiano, Eichenbaum, and Evans (2005), we assume investment adjustment costs in the production of capital. Law of motion for capital is as follows:

$$
K_{t+1}^{u}=\left[1-S\left(\frac{I_{t}}{\left(1+g_{s s}\right) I_{t-1}}\right)\right] I_{t}+\left(1-\delta_{k}\right) K_{t}^{u}
$$

where $g_{s s} \equiv \bar{\mu}$ is the steady state growth rate of $Z_{t}$. Utility maximization delivers the first order condition linking the inter-temporal consumption smoothing to the marginal utility of holding the risk-free bond

$$
1=\beta \mathbb{E}_{t}\left[\frac{\Lambda_{t+1}}{\Lambda_{t}}\left(1+i_{t}\right) \frac{P_{t}}{P_{t+1}}\right]
$$


The stochastic discount factor in period $t+1$ is given by:

$$
Q_{t, t+1}=\beta \frac{\Lambda_{t+1}}{\Lambda_{t}} \frac{P_{t}}{P_{t+1}}
$$

where $\Lambda_{t}$ is the marginal utility of consumption given by:

$$
\Lambda_{t}=\frac{1}{C_{t}-h C_{t-1}}-\frac{h \beta}{C_{t+1}-h C_{t}}
$$

The household does not choose hours directly. Rather each type of worker is represented by a wage union who sets wages on a staggered basis. Consequently the household supplies labor at the posted wages as demanded by firms.

We introduce capital accumulation through households. Solving household problem for investment and capital yields the Euler condition for capital:

$$
q_{t}=\beta \mathbb{E}_{t}\left[\frac{\Lambda_{t+1}}{\Lambda_{t}}\left(\frac{R_{t+1}^{K}}{P_{t+1}} u_{t+1}-a\left(u_{t+1}\right)+q_{t+1}\left(1-\delta_{k}\right)\right)\right]
$$

where the (relative) price of installed capital $q_{t}$ is given by

$$
\begin{aligned}
& q_{t}\left[1-S\left(\frac{I_{t}}{\left(1+g_{s s}\right) I_{t-1}}\right)-S^{\prime}\left(\frac{I_{t}}{\left(1+g_{s s}\right) I_{t-1}}\right) \frac{I_{t}}{\left(1+g_{s s}\right) I_{t-1}}\right] \\
& +\beta \frac{\Lambda_{t+1}}{\Lambda_{t}} q_{t+1} \frac{1}{\left(1+g_{s s}\right)}\left(\frac{I_{t+1}}{I_{t}}\right)^{2} S^{\prime}\left(\frac{I_{t+1}}{\left(1+g_{s s}\right) I_{t}}\right)=1
\end{aligned}
$$

Choice of capital utilization rate yields:

$$
\frac{R_{t}^{K}}{P_{t}}=a^{\prime}\left(u_{t}\right)
$$

\subsubsection{Wage Setting}

Wage Setting follows Erceg, Henderson, and Levin (2000) and is relatively standard. Perfectly competitive labor agencies combine $j$ type labor services into a homogeneous labor composite $L_{t}$ according to a Dixit-Stiglitz aggregation:

$$
L_{t}=\left[\int_{0}^{1} L_{j, t}^{\frac{1}{1+\lambda_{w}}} d j\right]^{1+\lambda_{w}}
$$

where $\lambda_{w}>0$ is the nominal wage markup. Labor unions representing workers of type $j$ set wages on a staggered basis following Calvo (1983), taking given the demand for their specific labor input:

$$
L_{j, t}=\left(\frac{W_{j, t}}{W_{t}}\right)^{-\frac{1+\lambda_{w}}{\lambda_{w}}} L_{t}, \quad \text { where } W_{t}=\left[\int_{0}^{1} W_{j, t}^{\frac{-1}{\lambda_{w}}} d j\right]^{-\lambda_{w}}
$$


In particular, with probability $1-\theta$, the type- $j$ union is allowed to re-optimize its wage contract and it chooses $\tilde{W}$ to minimize the disutility of working for laborer of type $j$, taking into account the probability that it will not get to reset wage in the future. The first order condition for this problem is given by:

$$
\mathbb{E}_{t} \sum_{s=0}^{\infty}\left(\beta \theta_{w}\right)^{s} \Lambda_{t+s}\left[\left(1+\tau_{t}^{W}\right) \tilde{W}_{t}-\left(1+\lambda_{w}\right) \omega \frac{L_{j, t+s}^{v}}{\Lambda_{t+s}}\right] L_{j, t+s}=0
$$

By the law of large numbers, the probability of changing the wage corresponds to the fraction of types who actually change their wage. Consequently, the nominal wage evolves according to:

$$
W_{t}^{\frac{1}{\lambda_{w}}}=\left(1-\theta_{w}\right) \tilde{W}_{t}^{\frac{1}{\lambda_{w}}}+\theta_{w} W_{t-1}^{\frac{1}{\lambda_{w}}}
$$

where the nominal wage inflation and price inflation are related to each other:

$$
\pi_{t}^{w}=\frac{W_{t}}{W_{t-1}}=\frac{w_{t}}{w_{t-1}} \frac{1}{\pi_{t}} \frac{1}{1+g_{t}}
$$

where $\pi_{t} \equiv \frac{P_{t}}{P_{t-1}}$ is the inflation rate, $w_{t} \equiv \frac{W_{t}}{P_{t} Z_{t}}$ is the productivity adjusted real wage and $g_{t}$ is the growth rate of $Z_{t}$.

\subsection{Government}

The central bank follows a Taylor rule in setting the nominal interest rate. It responds to deviations in inflation, output and output growth rate from time-t natural allocations.

$$
\frac{1+i_{t}}{1+i_{s S}}=\left(\frac{1+i_{t-1}}{1+i_{s S}}\right)^{\rho_{R}}\left[\left(\frac{\pi_{t}}{\pi_{s S}}\right)^{\phi_{\pi}}\left(\frac{Y_{t}}{Y_{t}^{f, t}}\right)^{\phi_{y}}\right]^{1-\rho_{R}}\left(\frac{Y_{t} / Y_{t-1}}{Y_{t}^{f, t} / Y_{t-1}^{f, t-1}}\right)^{\phi_{d y}} \epsilon_{t}^{m p}
$$

where $i_{s s}$ is the steady state nominal interest rate, $Y_{t}^{f, t}$ is the time-t natural output, $\rho_{R}$ determines interest-rate smoothing and $\epsilon_{t}^{m p} \sim N\left(0, \sigma_{r}\right)$ is the monetary policy shock.

We assume government balances budget every period:

$$
P_{t} T_{t}=\tau^{p} \int_{0}^{1} p_{i t} x_{i t} d i+\tau^{w} W_{t} L_{t}+P_{t} G_{t}
$$

where $G_{t}$ is the government spending, which is determined exogenously as as a fraction of GDP

$$
G_{t}=\left(1-\frac{1}{\lambda_{t}^{g}}\right) Y_{t}
$$

where the government spending shock follows the process:

$$
\log \lambda_{t}^{g}=\left(1-\rho_{g}\right) \lambda^{g}+\rho_{g} \log \lambda_{t-1}^{g}+\epsilon_{t}^{g} ; \quad \epsilon_{t}^{g} \sim N\left(0, \sigma_{g}\right)
$$




\section{5. $\quad$ Market Clearing}

$$
Y_{t}=C_{t}+I_{t}+a\left(u_{t}\right) K_{t}^{u}+G_{t}
$$

\subsection{Simulations}

Figure 8 plots the model-implied impulse responses for output, capital stock, real interest rate and capital to utilization adjusted TFP after a monetary policy shock. The exogenous shock is calibrated to generate a 100 basis point increase in nominal interest rate, and its persistence is fixed to match the persistence of real interest rate gap in the data. The IRFs for output and capital stock are plotted in deviations from an exogenous trend. For real interest rate, we plot the actual path of real interest rate, while the exogenous trend is real interest rate fixed at $3 \mathrm{pp}$. Capital to utilization adjusted TFP ratio is in deviation from steady state ratio. Time is in quarters.

Figure 8: Response of Output, Capital Stock, Real interest rate and Capital to TFP ratio to 1oo bps increase in nominal interest rate
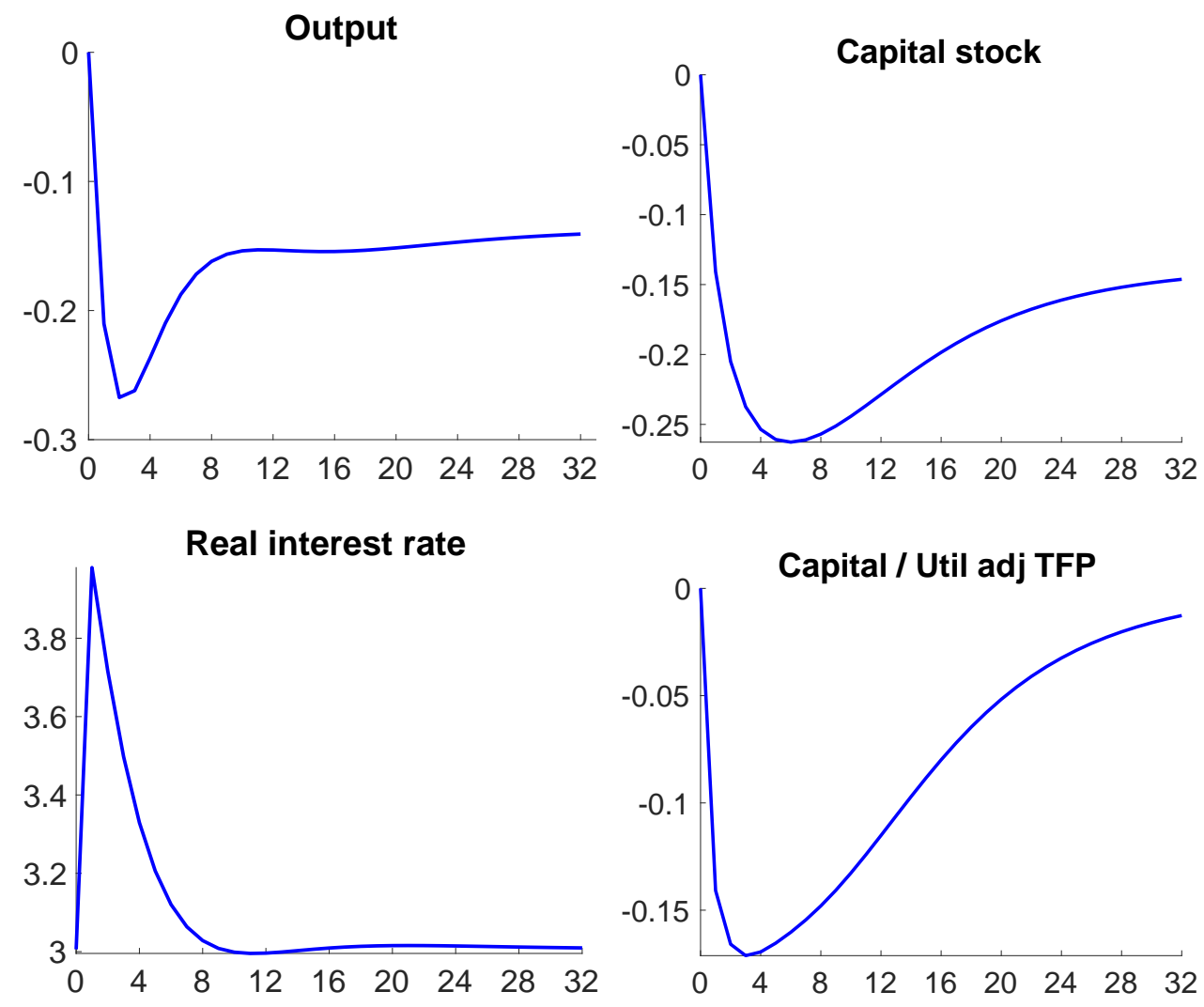

Notes: The figure plots the model-implied IRFs forOutput, Capital Stock, Real interest rate and Capital to utilization adjusted TFP. Time is in quarters. IRFs are traced following a one-time exogenous shock in the federal funds rate of 100 bps (annualized). The persistence of the shock is calibrated such that real interest rate returns to zero after 10 quarters. The IRFs for output and capital stock are plotted in deviations from an exogenous trend. For real interest rate, we plot the actual path of real interest rate, while the exogenous trend is real interest rate fixed at $3 \mathrm{pp}$. Capital to utilization adjusted TFP ratio is in deviation from steady state ratio.

The model can replicate the empirical estimated patterns. There is a persistent decline in capital stock, output and TFP. Capital to utilization adjusted TFP exhibits hump shaped response, with the 
ratio returning back to steady state.

5. Robustness

6. Conclusion 


\section{REFERENCES}

Angrist, J. D., Ò. Jordà, and G. M. Kuersteiner (2018). Semiparametric estimates of monetary policy effects: String theory revisited. Journal of Business and Economic Statistics 36(3), 371-387.

Anzoategui, D., D. Comin, M. Gertler, and J. Martinez (2018). Endogenous technology adoption and r\&d as sources of business cycle persistence. Technical report, New York University Working paper.

Barnichon, R. and C. Matthes (2018). Functional approximations of impulse responses (fair). Journal of Monetary Economics forthcoming.

Barro, R. J. (2013). Inflation and economic growth. Annals of Economics and Finance 14(1), 85-109.

Benigno, G. and L. Fornaro (2018). Stagnation traps. The Review of Economic Studies 85(3), 1425-1470.

Bergeaud, A., G. Cette, and R. Lecat (2016). Productivity trends in advanced countries between 1890 and 2012. Review of Income and Wealth 62(3), 420-444.

Bianchi, F., H. Kung, and G. Morales (2019). Growth, slowdowns, and recoveries. Journal of Monetary Economics forthcoming.

Caballero, R. J., T. Hoshi, and A. K. Kashyap (2008). Zombie lending and depressed restructuring in japan. The American Economic Review 98(5), 1943-1977.

Calvo, G. A. (1983). Staggered prices in a utility-maximizing framework. Journal of Monetary Economics 12(3), 383-398.

Christiano, L., M. Eichenbaum, and C. Evans (2005). Nominal rigidities and the dynamic effects of a shock to monetary policy. Journal of Political Economy 113(1).

Christiano, L. J., M. Eichenbaum, and C. L. Evans (1999). Monetary policy shocks: What have we learned and to what end? In J. B. Taylor and M. Woodford (Eds.), Handbook of Macroeconomics, Volume 1 of Handbook of Macroeconomics, Chapter 2, pp. 65-148. Elsevier.

Coibion, O., Y. Gorodnichenko, and M. Ulate (2017, July). The cyclical sensitivity in estimates of potential output. Working Paper 23580, National Bureau of Economic Research.

DeLong, B. J. and L. H. Summers (2012). Fiscal policy in a depressed economy. Brookings Papers on Economic Activity 1, 233-297.

Erceg, C. J., D. W. Henderson, and A. T. Levin (2000). Optimal monetary policy with staggered wage and price contracts. Journal of Monetary Economics 46(2), 281-313.

Erceg, C. J. and A. T. Levin (2014). Labor force participation and monetary policy in the wake of the great recession. Journal of Money, Credit and Banking 46(S2), 3-49.

Evans, C. L. (1992). Productivity shocks and real business cycles. Journal of Monetary Economics 29(2), 191-208.

Fernald, J. (2014). A quarterly, utilization-adjusted series on total factor productivity. Working Paper Series 2012-19, Federal Reserve Bank of San Francisco. 
Fischer, S. (1983, November). Inflation and growth. Working Paper 1235, National Bureau of Economic Research.

Galí, J. (2016). Hysteresis and the european unemployment problem revisited. Technical report, National Bureau of Economic Research.

Garga, V. and S. R. Singh (2016). Output hysteresis and optimal monetary policy. Technical report, Brown University Mimeo.

Gertler, M. and P. Karadi (2015, January). Monetary Policy Surprises, Credit Costs, and Economic Activity. American Economic Journal: Macroeconomics 7(1), 44-76.

Gopinath, G., c. Kalemli-Özcan, L. Karkarabounis, and C. Villegas-Sánchez (2017). Capital allocation and productivity in south europe. Quarterly Journal of Economics 132(4), 1915-1967.

Hume, D. (1758). Essays and Treatises on Several Subjects. A. Millar, A. Kincaid, and A. Donaldson.

Imbs, J. M. (1999). Technology, growth and the business cycle. Journal of Monetary Economics 44(1), $65-80$.

Jordà, Ò. (2005, March). Estimation and Inference of Impulse Responses by Local Projections. American Economic Review 95(1), 161-182.

Jordà, O., M. Schularick, and A. M. Taylor (2016). The great mortgaging: housing finance, crises and business cycles. Economic Policy 31(85), 107-152.

Jordà, O., M. Schularick, and A. M. Taylor (2017). Macrofinancial history and the new business cycle facts. NBER Macroeconomics Annual 31(1), 213-263.

Jordà, O., M. Schularick, and A. M. Taylor (2019). Large and State-Dependent Effects of QuasiRandom Monetary Experiments. Journal of Monetary Economics forthcoming.

Justiniano, A., G. E. Primiceri, and A. Tambalotti (2013). Is there a trade-off between inflation and output stabilization? American Economic Journal: Macroeconomics 5(2), 1-31.

Kiyotaki, N. and S. Zhang (2017). Intangibles, inequality and stagnation.

Liu, E., A. Mian, and A. Sufi (2018). Low interest rates, market power, and productivity growth. mimeograph.

Lucas, R. E. (1996). Nobel lecture: Monetary neutrality. Journal of Political Economy 104(4), 661-682.

Moran, P. and A. Queraltó (2018). Innovation, productivity, and monetary policy. Journal of Monetary Economics.

Obstfeld, M., J. C. Shambaugh, and A. M. Taylor (2004). Monetary sovereignty, exchange rates, and capital controls: The trilemma in the interwar period. IMF Staff Papers 51(3S1), 75-108.

Obstfeld, M., J. C. Shambaugh, and A. M. Taylor (2005). The trilemma in history: Tradeoffs among exchange rates, monetary policies, and capital mobility. The Review of Economics and Statistics 87(3), $423-438$.

Ramey, V. (2016). Chapter 2 - macroeconomic shocks and their propagation. Volume 2 of Handbook of Macroeconomics, pp. $71-162$. Elsevier. 
Ramey, V. A. and S. Zubairy (2018). Government spending multipliers in good times and in bad: Evidence from us historical data. Journal of Political Economy 126(2), 850-901.

Romer, C. D. and D. H. Romer (2004, September). A new measure of monetary shocks: Derivation and implications. American Economic Review 94(4), 1055-1084.

Romer, P. M. (1990). Endogenous technological change. Journal of Political Economy 98.

Shambaugh, J. C. (2004). The effect of fixed exchange rates on monetary policy*. The Quarterly Journal of Economics 119(1), 301-352.

Smets, F. and R. Wouters (2007). Shocks and frictions in us business cycles: A bayesian dsge approach. American Economic Review 97(3), 586-606.

Stock, J. H. and M. W. Watson (2018). Identification and estimation of dynamic causal effects in macroeconomics using external instruments. The Economic Journal 128(610), 917-948.

Tenreyro, S. and G. Thwaites (2016, October). Pushing on a String: US Monetary Policy Is Less Powerful in Recessions. American Economic Journal: Macroeconomics 8(4), 43-74.

Wieland, J. F. and M.-J. Yang (2016). Financial dampening. Technical report, National Bureau of Economic Research.

Yellen, J. L. (2016). Macroeconomic research after the crisis. Speech at the "The Elusive 'Great' Recovery: Causes and Implications for Future Business Cycle Dynamics" conference, Federal Reserve Bank of Boston, October. 


\section{Appendix: Data Sources and Calculations}

\section{Appendix: Related Graphs}

Figure A1: Baseline response to 10o bps Romer and Romer (2004) shock
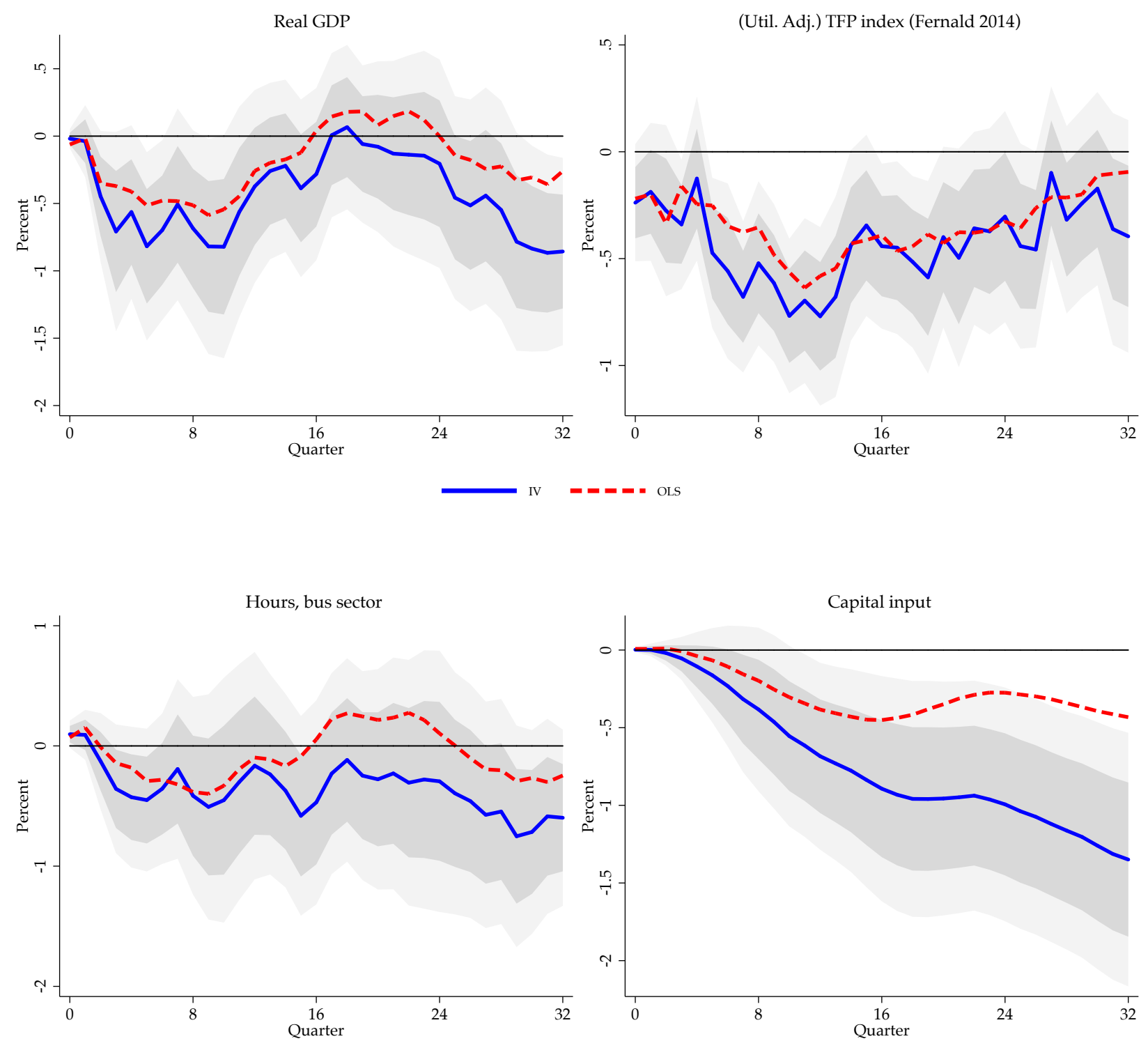

Notes: Response to a 100 bps shock in overnight federal funds rate rate instrumented with policy forecast residuals (Romer and Romer, 2004; Wieland and Yang, 2016). Responses of real GDP and utilization-adjusted TFP for US. Quarterly sample: 1969-Q1: 2007-Q4. See text. 


\section{APPENDIx: DSGE MODEL}

\section{Stationary Allocation}

We normalize the following variables :

$$
\begin{gathered}
y_{t}=Y_{t} / Z_{t} \\
c_{t}=C_{t} / Z_{t} \\
k_{t}=K_{t} / Z_{t} \\
k_{t}^{u}=K_{t}^{u} / Z_{t-1} \\
\mathbb{I}_{t}=I_{t} / Z_{t} \quad \text { capital investment } \\
G_{t}=G_{t} / Z_{t} \quad \text { Govt Spending } \\
w_{t}=W_{t} /\left(Z_{t} P_{t}\right) \\
r_{t}^{k}=R_{t}^{k} / P_{t} \\
\lambda_{t}=\Lambda_{t} Z_{t} \\
\tilde{\Gamma}_{t} \equiv \frac{\Gamma_{t}}{P_{t} Z_{t}}
\end{gathered}
$$

Definition 1 (normalized equilibrium). 19 endogenous variables $\left\{\lambda_{t}, g_{t+1}, i_{t}, \pi_{t}, \pi_{t}^{w}, X_{1 t}^{p}, X_{2 t}^{p}, X_{i t}^{w}\right.$, $\left.X_{2 t}^{w}, c_{t}, y_{t}, z_{t}, k_{t+1}^{u}, r_{t}^{K}, \mathbb{I}_{t}, q_{t}, u_{t}, k_{t}, w_{t}, L_{t}\right\}, 3$ shocks $\left\{\lambda_{t}^{g}, \epsilon_{t}^{m p}, \mu_{t}\right\}$ given the natural rate allocation variables $\left\{y_{t}^{f}, g_{t+1}^{f}\right\}$.

Consumption Euler Equation

$$
\begin{gathered}
1=\beta \mathbb{E}_{t}\left[\frac{\lambda_{t+1}}{\lambda_{t}\left(1+g_{t+1}\right)} \frac{1+i_{t}}{\pi_{t+1}}\right] \\
\lambda_{t}=\frac{1}{c_{t}-\frac{h c_{t-1}}{1+g_{t}}}-\frac{h \beta}{c_{t+1}\left(1+g_{t+1}\right)-h c_{t}}
\end{gathered}
$$

Price-Setting

$$
\begin{gathered}
\frac{X_{1 t}^{p}}{X_{2 t}^{p}}=\left(\frac{1-\theta_{p} \pi_{t}^{\frac{1}{\lambda_{p}}}}{1-\theta_{p}}\right)^{-\lambda_{p}} \\
X_{1 t}^{p}=\left(1+\lambda_{p}\right) \lambda_{t} y_{t}+\theta_{p} \beta \pi_{t+1}^{\frac{1+\lambda_{p}}{\lambda_{p}}} X_{1 t+1}^{p} \\
X_{2 t}^{p}=\lambda_{t} y_{t}+\theta_{p} \beta \pi_{t+1}^{\frac{1}{\lambda_{p}}} X_{2 t+1}^{p}
\end{gathered}
$$

Wage-Setting

$$
\begin{gathered}
\frac{X_{1 t}^{w}}{X_{2 t}^{w}}=\left(\frac{1-\theta_{w}\left(\pi_{t}^{w}\right)^{\frac{1}{\lambda_{w}}}}{1-\theta_{w}}\right)^{-\lambda_{w}+\left(1+\lambda_{w}\right) v} \\
X_{1 t}^{w}=\left(1+\lambda_{w}\right) \omega L_{t}^{1+v}+\theta_{w} \beta \pi_{W, t+1}^{\frac{\left(1+\lambda_{w}\right)(1+v)}{\lambda_{w}}} X_{1 t+1}^{w}
\end{gathered}
$$




$$
\begin{gathered}
X_{2 t}^{w}=\left(1+\tau^{w}\right) \lambda_{t} w_{t} L_{t}+\theta_{w} \beta \pi_{W, t+1}^{\frac{1}{\lambda_{w}}} X_{2 t+1}^{w} \\
\pi_{t}^{w}=\frac{w_{t}}{w_{t-1}} \pi_{t}\left(1+g_{t}\right)
\end{gathered}
$$

Capital Investment

$$
\begin{gathered}
k_{t+1}^{u}=\left[1-S\left(\frac{\mathbb{I}_{t}}{\mathbb{I}_{t-1}} \frac{1+g_{t}}{1+g_{s s}}\right)\right] \mathbb{I}_{t}+\left(1-\delta_{k}\right) \frac{k_{t}^{u}}{1+g_{t}} \\
q_{t}=\beta \mathbb{E}_{t}\left[\frac{\lambda_{t+1}}{\lambda_{t}\left(1+g_{t+1}\right)}\left(r_{t+1}^{K} u_{t+1}-a\left(u_{t+1}\right)+q_{t+1}\left(1-\delta_{k}\right)\right)\right] \\
q_{t}\left[1-S\left(\frac{\mathbb{I}_{t}}{\mathbb{I}_{t-1}} \frac{1+g_{t}}{1+g_{s s}}\right)-S^{\prime}\left(\frac{\mathbb{I}_{t}}{\mathbb{I}_{t-1}} \frac{1+g_{t}}{1+g_{s s}}\right) \frac{\mathbb{I}_{t}}{\mathbb{I}_{t-1}} \frac{1+g_{t}}{1+g_{s s}}\right] \\
+\beta \frac{\lambda_{t+1}}{\lambda_{t}} q_{t+1} \frac{1+g_{t+1}}{1+g_{s s}}\left(\frac{\mathbb{I}_{t+1}}{\mathbb{I}_{t}}\right)^{2} S^{\prime}\left(\frac{\mathbb{I}_{t+1}}{\mathbb{I}_{t}} \frac{1+g_{t+1}}{1+g_{s s}}\right)=1
\end{gathered}
$$

Capital utilization rate

$$
\begin{gathered}
k_{t}=u_{t} \frac{k_{t}^{u}}{1+g_{t}} \\
r_{t}^{K}=a^{\prime}\left(u_{t}\right)
\end{gathered}
$$

Production Technologies

$$
\begin{gathered}
y_{t}=k_{t}^{\alpha} L_{t}^{1-\alpha} \\
r_{t}^{k}=\alpha \frac{y_{t}}{k_{t}} \\
w_{t}=(1-\alpha) \frac{y_{t}}{L_{t}}
\end{gathered}
$$

Endogenous Growth

$$
g_{t}=\log Z_{t}-\log Z_{t-1}=\mu_{t}+\eta \log \left(y_{t-1} / y_{t-1}^{f}\right)
$$

\section{Government}

$$
\frac{1+i_{t}}{1+i_{s s}}=\left(\frac{1+i_{t-1}}{1+i_{s S}}\right)^{\rho_{R}}\left[\left(\frac{\pi_{t}}{\pi_{s s}}\right)^{\phi_{\pi}}\left(\frac{y_{t}}{y_{t}^{f}}\right)^{\phi_{y}}\right]^{1-\rho_{R}}\left(\frac{y_{t} / y_{t-1}}{y_{t}^{f} / y_{t-1}^{f}} \frac{1+g_{t}}{1+g_{t}^{f}}\right)^{\phi_{d y}} \epsilon_{t}^{m p}
$$

Market Clearing

$$
y_{t}=c_{t}+\mathbb{I}_{t}+a\left(u_{t}\right) \frac{k_{t}^{u}}{1+g_{t}}+\left(1-\frac{1}{\lambda_{t}^{g}}\right) y_{t}
$$

Shocks

$$
\begin{gathered}
\log \lambda_{t}^{g}=\left(1-\rho_{g}\right) \lambda^{g}+\rho_{g} \log \lambda_{t-1}^{g}+\epsilon_{t}^{g} ; \quad \epsilon_{t}^{g} \sim N\left(0, \sigma_{g}\right) \\
\epsilon_{t}^{m p} \sim N\left(0, \sigma_{r}\right)
\end{gathered}
$$

